\title{
KENDALI OPTIMAL PADA MODEL PENYEBARAN PENYAKIT DIFTERI DENGAN TINGKAT IMUNITAS ALAMI PADA INDIVIDU TERPAPAR
}

\author{
N. Izzati ${ }^{1}$ dan A. Andriani² \\ 1Fakultas Teknik, Universitas Hasyim Asy'ari \\ 2Fakultas Teknologi Informasi, Universitas Hasyim Asy'ari \\ 1nailulizzati@unhasy.ac.id, 2anitaandriani@unhasy.ac.id
}

\begin{abstract}
Indonesia is one of the countries where has not been free from diphtheria outbreak. During 2017-2019, there were 2870 diphtheria cases with 96 deaths. With the mortality rate $5-20 \%$, makes studies regarding diphtheria prevention and management strategies become important to do. In this study, a SEIQR mathematical model was constructed by considering the factor of natural immunity rate in exposed individuals. Then, by considering the complete basic immunization coverage and the proportion of the number of individuals with natural immunity rate as control variables, the optimal control problem is formulated to minimize the number of infected poopulation. Optimal control using DOTcvpSB toolbox obtained that the number of exposed population in the model decreased from $4.9 \%$ to $0.75 \%$, and the number of infected population decreased from $3.1 \%$ to $0.32 \%$.
\end{abstract}

Keywords : Diphtheria, DOTcvpSB, Natural Immunity Rate, Optimal control.

\begin{abstract}
ABSTRAK
Indonesia adalah salah satu negara yang belum terbebas dari wabah difteri. Selama 2017-2019, tercatat 2870 kasus difteri dengan 96 kematian. Dengan tingkat kematian difteri 5-20\%, studi mengenai strategi pencegahan dan penanganan penyakit difteri menjadi penting untuk dilakukan. Dalam penelitian ini dibangun sebuah model matematika SEIQR dengan mempertimbangkan faktor tingkat imunitas alami pada individu terpapar. Dengan memandang cakupan imunisasi dasar lengkap dan proporsi jumlah individu dengan tingkat imunitas alami sebagai variabel kendali, diformulasikan masalah kendali optimal untuk meminimumkan jumlah penderita penyakit difteri. Pengendalian optimal menggunakan toolbox DOTcvpSB menghasilkan bahwa jumlah populasi terpapar dalam model menurun dari $4,9 \%$ menjadi $0,75 \%$, dan jumlah populasi terinfeksi menurun dari $3,1 \%$ menjadi $0,32 \%$.
\end{abstract}

Kata kunci : : Difteri, DOTcvpSB, Kendali optimal, Tingkat imunitas alami. 


\section{PENDAHULUAN}

Difteri adalah suatu penyakit menular akut yang disebabkan oleh bakteri Corynebacterium diptheriae. Penyakit difteri ditandai dengan peradangan pada tempat infeksi, khususnya pada selaput mukosa faring, laring, tonsil, hidung dan kulit. Sebanyak $94 \%$ kasus difteri menyerang tonsil dan faring, beberapa gejalanya adalah nyeri pada tenggorakan, nyeri ketika menelan makanan dan demam tinggi. Tingkat kematian penyakit ini adalah $10 \%$ jika penderita mendapatkan pengobatan dengan baik dan $50 \%$ jika penderita tidak berobat dan tidak mempunyai imunitas. Pada anak usia kurang dari 5 tahun kematian karena difteri adalah sekitar $5-10 \%$, sedangkan pada orang dewasa mencapai $20 \%$. Penyebab kematian karena difteri sebagian besar adalah karena adanya sumbatan jalan nafas, kerusakan otot jantung, serta kelainan susunan saraf pusat dan ginjal (Kementerian Kesehatan Republik Indonesia, 2017).

Dari tahun ke tahun, kasus difteri di Indonesia masih terus ada. Tahun 2017 tercatat 622 kasus dan 32 kematian. Tahun 2018 tercatat 1.386 kasus dan 29 kematian (Kementerian Kesehatan Republik Indonesia, 2018). Tahun 2019 tercatat 530 kasus dengan 23 kematian (Kementerian Kesehatan Republik Indonesia, 2019). Meskipun berbahaya dan cukup mematikan, difteri dapat dicegah dengan melakukan imunisasi lengkap dan rutin sesuai dengan usia anak (Kementerian kesehatan, 2017). Imunisasi terhadap penyakit difteri diberikan oleh pemerintah secara gratis. Dalam tiga tahun terakhir, persentase kabupaten/kota yang mencapai $80 \%$ imunisasi dasar lengkap pada bayi menurut provinsi secara berturut-turut adalah sebesar $85,41 \%, 72,76 \%$, dan $71,98 \%$. Akan tetapi, terdapat provinsi dengan cakupan imunisasi dasar lengkap di bawah 50\%, seperti Aceh, Sumatera Barat, NTT, Kalimantan Barat, Kalimantan Utara, Papua, dan Papua Barat (Kementerian Kesehatan Republik Indonesia, 2019).

Selain cakupan imunisasi dasar lengkap, faktor imunitas alami juga diperlukan untuk menghadapi paparan penyakit difteri. Imunitas alami dapat diperoleh melalui gizi yang cukup, gaya hidup yang sehat, serta kebersihan diri dan lingkungan yang baik. Sebuah studi menyebutkan bahwa lingkungan fisik rumah seperti jenis lantai dan luas ventilasi juga berpengaruh terhadap penyebaran difteri. Jenis lantai yang lembab dapat membuat daya tahan tubuh seseorang menurun dan rentan terhadap penyakit infeksi. Selain itu, kurangnya ventilasi di dalam rumah dan kebiasaan yang jarang membuka jendela menyebabkan aliran udara terganggu sehingga bakteri mudah menyerang (Prabowo \& Iriani, 2019).

Penelitian tentang penyakit difteri terus dikembangkan sebagai salah satu usaha untuk meminimalkan penyebaran penyakit tersebut. Di antaranya adalah melalui model matematika untuk menggambarkan dinamika penularan penyakit difteri. Berbagai tipe model interaksi yang digunakan antara lain SIR (Miao dkk., 2017), SEIR (Ilahi \& Widiana, 2018), SIQR (Puspita dkk., 2017), SEIQR (Izzati dkk., 2020; Izzati \& Andriani, 2021), dan lain sebagainya. Dalam penelitian ini, dikonstruksi model matematika SEIQR, dengan mempertimbangkan tingkat imunitas alami dan cakupan imunisasi dasar sebagai dua faktor yang menyumbang laju penularan penyakit difteri. Selanjutnya, 
diformulasikan masalah kendali optimal pada model yang dikonstruksi sehingga ditemukan nilai optimal dari cakupan imunisasi dasar dan proporsi individu dengan imunitas alami yang kuat dengan tujuan agar jumlah penderita penyakit difteri dapat diminimumkan.

\section{METODE PENELITIAN}

Penelitian ini dilakukan dengan beberapa tahapan, yakni pengumpulan data, konstruksi model, formulasi masalah kendali optimal, simulasi numerik, dan penarikan simpulan. Pada tahap pengumpulan data, dilakukan berbagai kajian ilmiah, pengumpulan informasi tentang penyebaran penyakit difteri, meliputi penyebab, proses penularan dan penyembuhan, tingkat kematian, serta cara pencegahan. Pengumpulan informasi terkait penyebaran penyakit difteri dilakukan dengan cara melakukan library research dan wawancara dengan dokter klinik. Setelah informasi dan data terkumpul, mulailah dikonstruksi model matematika untuk menggambarkan penyebaran penyakit difteri dengan variabel keadaan $\mathrm{S}$ (jumlah individu rentan), E (jumlah individu terpapar), I (jumlah individu terinfeksi), Q (jumlah individu dikarantina), dan R (jumlah individu sembuh).

Pada tahap selanjutnya, diformulasi masalah kendali optimal yang meliputi konstruksi suatu fungsi objektif dan kendala fisis dari variabel keadaan dan kendali. Fungsi objektif yang dibangun bertujuan untuk meminimumkan jumlah populasi terinfeksi. Setelah masalah kendali optimal diformulasikan, tahap selanjutnya adalah menyelesaikannya agar variabel kendali yang optimal dapat diketahui. Masalah kendali optimal tersebut diselesaikan secara numerik menggunakan toolbox DOTcvpSB. Sebagian dari nilai parameter pada simulasi numerik bersumber dari penelitian terdahulu, sebagian lagi hasil pengolahan data, dan sebagian yang lain diperoleh dengan menerapkan asumsi. Terakhir, ditarik kesimpulan berdasarkan hasil simulasi numerik.

\section{HASIL DAN PEMBAHASAN}

Pada bagian ini dibahas formulasi dari masalah kendali optimal, meliputi konstruksi model matematika penyebaran penyakit difteri dengan vaksinasi dan kekebalan (imunitas) alami pada individu terpapar, kendala fisis dari variabel keadaan dan variabel kendali, serta fungsi objektif.

\subsection{Konstruksi Model Matematika}

Misalkan pada suatu wilayah dengan total populasi $N$, diasumsikan terdapat penyakit difteri. Berdasarkan status individu terhadap penyakit difteri, total populasi $N$ terbagi menjadi lima kelompok, yakni rentan (susceptible), terpapar (exposed), terinfeksi (infected), dalam karantina (quarantine), dan sembuh (recovered). Individu-individu yang tidak mendapatkan vaksinasi termasuk dalam kelompok rentan $(S)$, sedangkan yang mendapat vaksinasi diasumsikan kebal dan termasuk dalam kelompok sembuh $(R)$. Proporsi populasi yang divaksinasi diperoleh dari cakupan imunisasi dasar terhadap jumlah kelahiran. 
Adanya tingkat interaksi antara kelompok rentan dengan kelompok terinfeksi memungkinkan terjadinya transmisi atau penularan penyakit difteri. Individu rentan yang berinteraksi dengan individu terinfeksi disebut dengan individu terpapar $(E)$. Individu terpapar dalam suatu kurun waktu tertentu dapat terinfeksi oleh penyakit difteri apabila tidak memiliki tingkat imunitas alami yang baik. Tingkat imunitas alami yang baik dapat diperoleh dari nutrisi yang cukup, gaya hidup sehat, dan kebersihan diri serta lingkungan yang baik. Individu terpapar yang memiliki tingkat imunitas alami yang baik dimungkinkan untuk tidak terinfeksi oleh penyakit difteri dan diasumsikan statusnya termasuk dalam kelompok rentan. Sedangkan individu yang terinfeksi (I) akan mendapatkan perawatan dan dikarantina. Diasumsikan bahwa laju perubahan individu terpapar (yang memiliki tingkat imunitas lemah) menjadi terinfeksi, sama dengan laju perubahan individu terpapar (yang memiliki tingkat imunitas kuat) menjadi rentan kembali.

Individu terinfeksi yang dirawat dalam karantina $(Q)$ bisa jadi sembuh atau meninggal. Individu yang sembuh $(R)$ diasumsikan tidak akan tertular penyakit difteri kembali. Dalam model ini, diasumsikan pula bahwa jumlah populasi dipengaruhi oleh tingkat kematian alami. Berdasarkan asumsi dan batasan yang dipertimbangkan, diperoleh diagram kompartemen dari model yang dimaksud (lihat Gambar 1). Secara matematis, model tersebut dinyatakan dalam sistem persamaan diferensial (1)-(5).

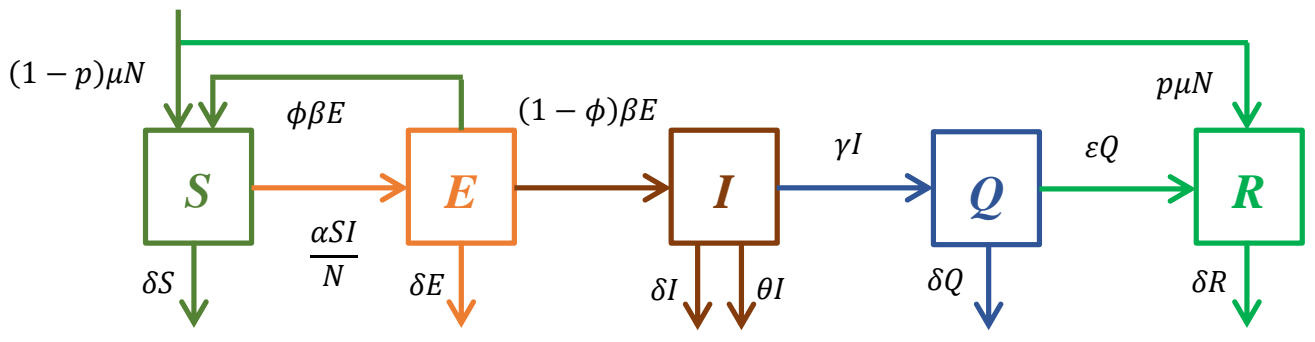

Gambar 1 : Diagram kompartemen model penyebaran penyakit difteri dengan vaksinasi dan tingkat imunitas alami

$$
\begin{aligned}
& \frac{d S}{d t}=(1-p) \mu N-\frac{\alpha S I}{N}-\delta S+\phi \beta E \\
& \frac{d E}{d t}=\frac{\alpha S I}{N}-\beta E-\delta E \\
& \frac{d I}{d t}=(1-\phi) \beta E-\gamma I-\delta I-\theta I \\
& \frac{d Q}{d t}=\gamma I-\varepsilon Q-\delta Q \\
& \frac{d R}{d t}=p \mu N+\varepsilon Q-\delta R
\end{aligned}
$$

Parameter-parameter dalam sistem persamaan (1)-(5) didefinisikan sebagai berikut: $\mu$ adalah tingkat kelahiran, $\delta$ adalah tingkat kematian alami, $p$ adalah cakupan imunisasi dasar, $\alpha$ adalah tingkat interaksi antara kelompok rentan dengan kelompok terinfeksi, $\phi$ adalah 
proporsi individu terpapar dengan tingkat imunitas alami yang kuat, $\beta$ adalah laju perubahan $E$ menjadi $I$ atau $S, \gamma$ adalah laju penanganan, $\varepsilon$ laju penyembuhan, $\theta$ tingkat kematian akibat difteri. Semua nilai parameter-parameter tersebut adalah bilangan positif.

\subsection{Masalah Kendali Optimal}

Dengan mempertimbangkan bahwa cakupan imunisasi dasar dan tingkat imunitas alami pada populasi terpapar berpengaruh besar dalam penyebaran penyakit difteri, maka kedua faktor tersebut dapat dipandang sebagai variabel kendali, misalkan cakupan imunisasi dasar ( $p$ ) sebagai variabel kendali $u_{1}$ sedangkan proporsi populasi terpapar yang memiliki imunitas alami yang kuat $(\phi)$ sebagai variabel kendali $u_{2}$.

Fungsi objektif yang dibangun dalam masalah kendali optimal ini, bertujuan untuk meminimalkan jumlah populasi terinfeksi. Secara matematis, hal ini dinyatakan sebagai persamaan (6).

$$
\min J=\int_{t_{0}}^{t_{f}} I(t) d t
$$

Dengan demikian, masalah kendali optimal yang diformulasikan bertujuan untuk menemukan nilai optimal dari cakupan imunisasi dasar dan proporsi populasi yang memiliki tingkat imunitas alami yang tinggi, sedemikian hingga jumlah subpopulasi terinfeksi dapat diminimalkan. Komponen utama dari masalah kendali optimal tersebut adalah: sistem persamaan (1)-(5), di mana $p=u_{1}$ dan $\phi=u_{2}$; dengan fungsi objektif (6); dan kendala fisis dari variabel keadaan adalah $S \geq 0, E \geq 0, I \geq 0, Q \geq 0, R \geq 0$, semua parameter bernilai positif, sedangkan variabel kendali memiliki interval $0 \leq u_{1} \leq 1$ dan $0 \leq u_{2} \leq 1$.

\subsection{Simulasi Numerik}

Dalam simulasi numerik, kondisi awal dari sistem disetting sebagai $S(0)=0,95, E(0)=$ $0, I(0)=0,05, Q(0)=0, R(0)=0$. Dengan kata lain, diasumsikan $95 \%$ dari total populasi adalah rentan difteri, dan $5 \%$ sisanya telah terinfeksi. Nilai parameter yang digunakan dalam simulasi numerik ditunjukkan pada Tabel 1. Dalam simulasi numerik dipertimbangkan dua buah skenario. Skenario A mempertimbangkan tingkat kelahiran dan kematian alami dalam dinamika sistem, dimana $\mu=0,019 \neq \delta=0,06$. Skenario B menerapkan asumsi bahwa tingkat kelahiran sama dengan tingkat kematian alami, sehingga total populasi dapat diasumsikan konstan. Dalam hal ini diambil nilai $\mu=\delta=0,01$. Skenario B dimaksudkan agar dinamika sistem yang terlihat, dapat fokus kepada perubahan jumlah populasi akibat penularan dan kematian penderita penyakit difteri. 
Tabel 1 : Nilai Parameter dalam Simulasi Numerik

\begin{tabular}{|c|c|c|}
\hline Parameter & Nilai & Sumber \\
\hline$\mu$ & 0,019 & (Kementerian PPN/BAPPENAS dkk., 2013) \\
$\delta$ & 0,006 & (Kementerian PPN/BAPPENAS dkk., 2013) \\
$\alpha$ & 0,57 & (Puspita dkk., 2017) \\
$\beta$ & 0,23 & (Fathoni dkk., 2015) \\
$\gamma$ & 0,5 & - \\
$\theta$ & 0,5 & (Puspita dkk., 2017) \\
& 0,05 & (Kementerian PPN/BAPPENAS dkk., 2013) \\
\hline
\end{tabular}

Hasil simulasi numerik dari skenario A ditunjukkan oleh Gambar 2 dan 3. Gambar 2 adalah dinamika sistem sebelum dilakukan pengendalian optimal. Dan Gambar 3 adalah dinamika sistem sesudah pengendalian optimal. Melalui simulasi, diketahui bahwa tanpa pengendalian optimal, jumlah populasi rentan yang awalnya $95 \%$ sempat menurun hingga $50 \%$ kemudian naik kembali hingga di posisi $70 \%$ pada hari ke-100. Jumlah populasi terpapar yang awalnya tidak ada, meningkat hingga di posisi $4,9 \%$. Jumlah populasi terinfeksi awalnya $5 \%$ menurun menjadi $3,1 \%$. Jumlah populasi dalam karantina meningkat, awalnya 0 menjadi $1,75 \%$. Sedangkan populasi sembuh mencapai $101 \%$. Dengan jumlah total populasi adalah $181 \%$ dari jumlah mula-mula, dan fungsi objektifnya mencapai 4,73 . Setelah dilakukan pengendalian optimal, pada hari ke-100, jumlah populasi rentan adalah $129 \%$, terpapar $0,75 \%$, terinfeksi $0,32 \%$, dikarantina $0,16 \%$, sembuh $66 \%$. Dengan total populasi $198 \%$ dan fungsi objektif mencapai 0,31 . Perlu dicatat bahwa total prosentase yang ditunjukkan adalah mengacu pada total populasi awal yang dipengaruhi oleh tingkat kelahiran dan kematian alami, oleh karenanya terdapat prosentasi yang lebih dari $100 \%$.

Hasil simulasi numerik dari skenario B ditunjukkan oleh Gambar 4 dan 5. Gambar 4 adalah trayektori solusi sistem sebelum dilakukan pengendalian optimal. Sedangkan Gambar 5 adalah sesudahnya. Sebelum dilakukan pengendalian optimal, hasil simulasi menunjukkan bahwa pada hari ke-100, jumlah populasi rentan 59\%, terpapar 0,64\%, terinfeksi $0,43 \%$, dikarantina $0,26 \%$, sembuh $34 \%$. Dengan total populasi adalah $94 \%$ dari total populasi awal, dan fungsi objektif mencapai 2,17. Dan setelah dilakukan pengendalian optimal, jumlah populasi rentan adalah $78 \%$, jumlah populasi terpapar, terinfeksi, dan dikarantina sangat kecil, mendekati $0 \%$, populasi sembuh $21 \%$. Dengan total populasi $99,5 \%$ dan fungsi objektif 0,28 . 


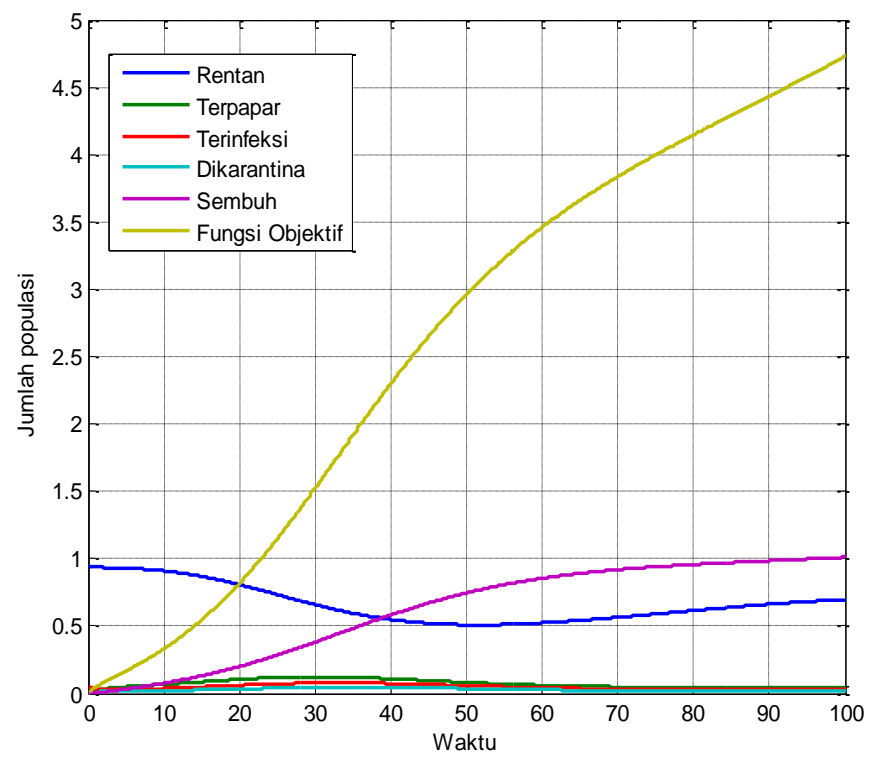

Gambar 2 : Dinamika Penyebaran Penyakit Difteri Pada Skenario A $(\mu>\delta)$ Sebelum Pengendalian Optimal.

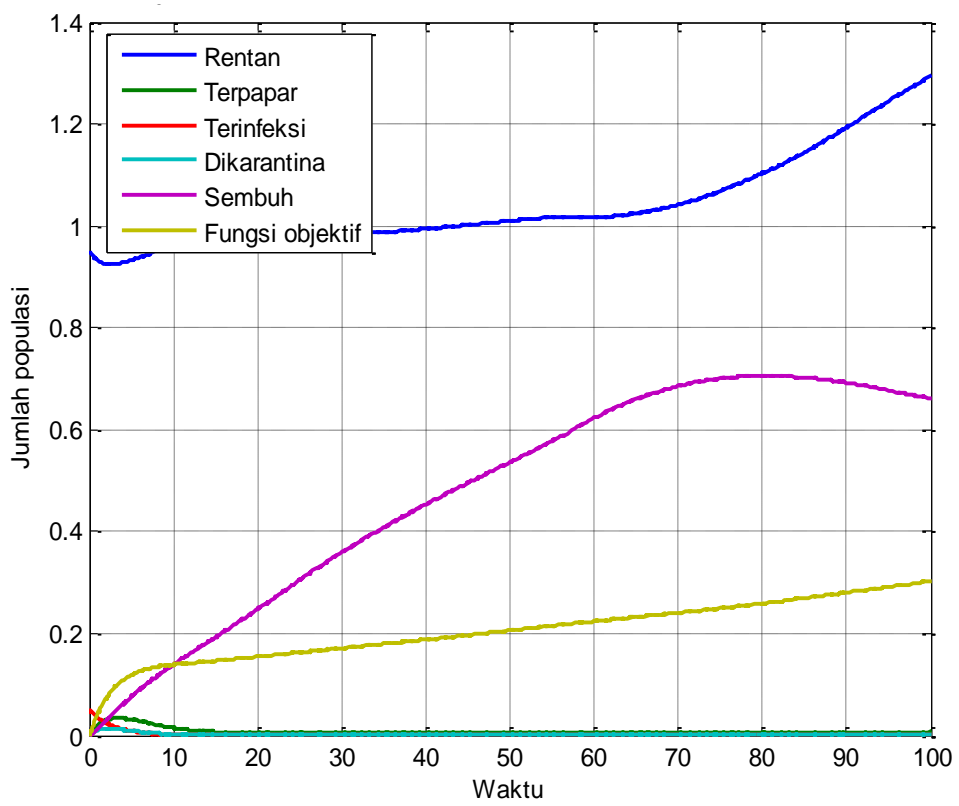

Gambar 3 : Dinamika Penyebaran Penyakit Difteri Pada Skenario A $(\mu>\delta)$ Sesudah Pengendalian Optimal. 


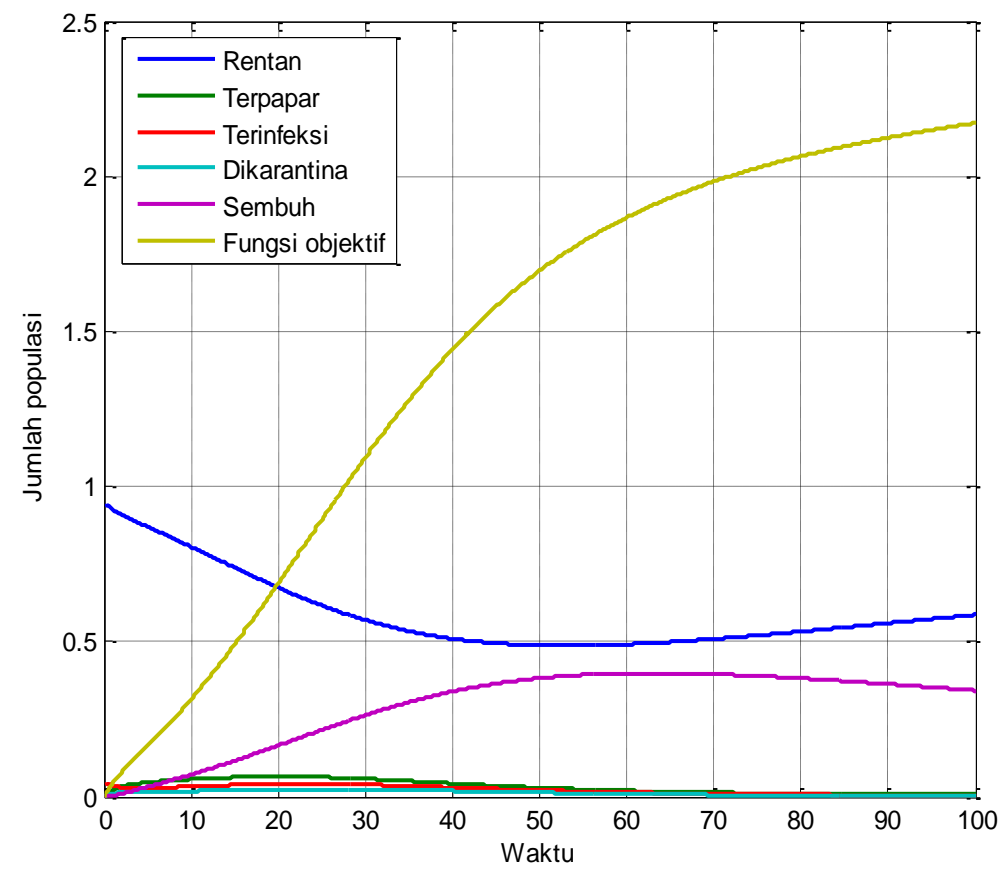

Gambar 4 : Dinamika Penyebaran Penyakit Difteri Pada Skenario B $(\mu=\delta)$ Sebelum Pengendalian Optimal.

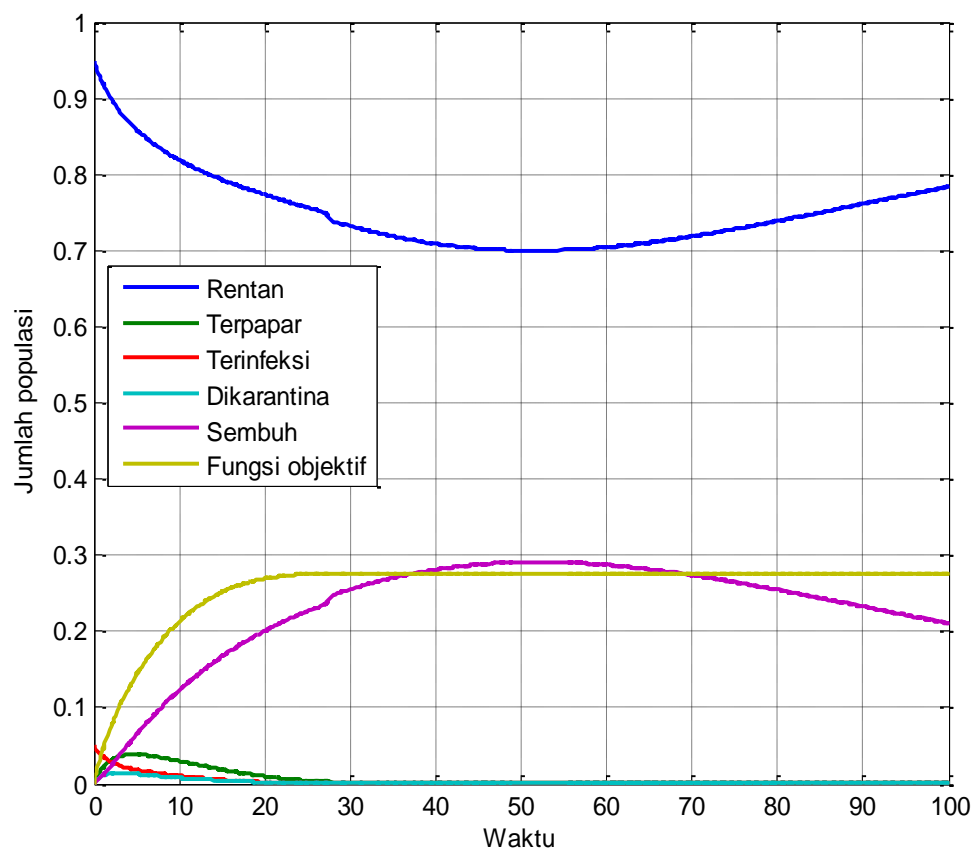

Gambar 5 : Dinamika Penyebaran Penyakit Difteri Pada Skenario B $(\mu=\delta)$ Sesudah Pengendalian Optimal. 
Tabel 2 : Perbandingan Jumlah Populasi Sebelum dan Sesudah Pengendalian Optimal

\begin{tabular}{|l|l|l|l|l|}
\hline \multirow{2}{*}{ Parameter } & \multicolumn{3}{l|}{ Skenario A } & \multicolumn{2}{l|}{ Skenario B } \\
\cline { 2 - 5 } & Sebelum & Sesudah & Sebelum & Sesudah \\
\hline Populasi rentan & 0,6969 & 1,2938 & 0,5866 & 0,7837 \\
\hline Populasi terpapar & 0,0492 & 0,0075 & 0,0064 & $0,0016 \times 10^{\wedge}(-4)$ \\
\hline Populasi terinfeksi & 0,0308 & 0,0032 & 0,0043 & $0,0094 \times 10^{\wedge}(-5)$ \\
\hline Populasi dikarantina & 0,0179 & 0,0016 & 0,0026 & $0,0053 \times 10^{\wedge}(-5)$ \\
\hline Populasi sembuh & 1,0110 & 0,6611 & 0,3426 & 0,2109 \\
\hline Total populasi & 1,8058 & 1,9672 & 0,9425 & 0,9946 \\
\hline Fungsi objektif & 4,7270 & 0,3036 & 2,1710 & 0,2766 \\
\hline
\end{tabular}

Perbandingan hasil simulasi numerik dari kedua skenario disajikan pada Tabel 2. Berdasarkan Tabel 2, diketahui bahwa dengan adanya pengendalian optimal yang diformulasikan, prosentase populasi rentan mengalami peningkatan, hal ini tentunya dipengaruhi oleh proporsi individu terpapar yang memiliki tingkat imunitas alami yang kuat. Apabila proporsinya tinggi, maka jumlah individu yang berubah statusnya dari terpapar menjadi kembali rentan juga tinggi. Selain itu, pengendalian optimal yang diformulasikan juga berhasil menurunkan prosentase populasi terpapar, terinfeksi, dikarantina, dan sembuh. Penurunan pada populasi terinfeksi tentunya membuat populasi dikarantina dan sembuh juga menurun. Dengan membandingkan total populasi pada skenario B, tampak bahwa kematian akibat penyakit difteri menyumbang berkurangnya $5 \%$ lebih total populasi, dan dengan pengendalian optimal, nilai tersebut dapat dikurangi sampai kurang dari $1 \%$.

\section{KESIMPULAN}

Berdasarkan hasil pengendalian optimal, diketahui bahwa dengan pengoptimalan cakupan imunisasi dasar lengkap dan proporsi jumlah individu dengan imunitas yang kuat, mampu menurunkan jumlah populasi terpapar dari 4,9\% menjadi 0,75\%, dan jumlah populasi terinfeksi dari 3,1\% menjadi $0,32 \%$. Bagaimanapun, nilai parameter yang digunakan dalam penelitian ini sebagian diperoleh dari asumsi, sehingga belum tentu sesuai dengan kenyataan. Oleh karena itu, penggunaan data dan asumsi yang lebih realistis akan menghasilkan simulasi yang lebih relevan.

\section{DAFTAR PUSTAKA}

[1]. Kementerian Kesehatan Republik Indonesia, Pedoman Pencegahan dan Pengendalian Difteri, Buku Pedoman Pencegahan dan Pengendalian Difteri, (Penyakit KLB), 2017, pp. 1-34.

[2]. Kementrian Kesehatan RI, Profil Kesehatan Indonesia 2018, Kementrian Kesehatan RI, 2018, pp. 210-2.

[3]. Kementrian Kesehatan RI (2019), Data dan Informasi Profil Kesehatan Indonesia 2019, Kementrian Kesehatan RI, 8(9), pp. 1-58. 
[4]. Prabowo, J. \& Iriani, D. U., Hubungan antara Faktor Lingkungan Fisik Rumah dan Karaktersitik Individu Terhadap Kejadian Difteri di Kabupaten Tangerang, Jurnal of Religion and Public Health, 2019, 1(1), pp. 20-25.

[5]. Miao, A. dkk., Threshold Dynamics of a Stochastic SIR Model with Vertical Transmission and Vaccination, Computational and Mathematical Methods in Medicine, 2017, p. 820183. doi: 10.1155/2017/4820183.

[6]. Ilahi, F. \& Widiana, A., The Effectiveness Of Vaccine In The Outbreak Of Diphtheria: Mathematical Model And Simulation, IOP Conference Series: Materials Science and Engineering, 2018, 434(1). doi: 10.1088/1757-899X/434/1/012006.

[7]. Puspita, G., Kharis, M. \& Supriyono, S., Pemodelan Matematika Pada Penyebaran Penyakit Difteri Dengan Pengaruh Karantina Dan Vaksinasi, Unnes Journal of Mathematics, 2017, 6(1), pp. 25-35. doi: 10.15294/ujm.v6i1.11867.

[8]. Izzati, N., Andriani, A. \& Robi' Aqolbi, R., Optimal Control Of Diphtheria Epidemic Model With Prevention And Treatment, Journal of Physics: Conference Series, 2020, p. 012042. doi: 10.1088/1742-6596/1663/1/012042.

[9]. Izzati, N. \& Andriani, A., Dynamical Analysis Of Diphtheria Epidemic Model With Natural Immunity Rate On Exposed Individuals, Journal of Physics: Conference Series, 2021, p. 012117. doi:10.1088/1742-6596/1869/1/012117.

[10]. Kementerian PPN/BAPPENAS, Proyeksi Penduduk Indonesia 2010-2035, Badan Pusat Statistik \& United Nations Population Fund, 2013, pp 34, 84-468.

[11]. Fathoni, M. I. A., Mardlijah, M. \& Hariyanto, H., Optimal Pada Model Epidemi Seit, Prosiding Seminar Nasional Matematika dan Pendidikan Matematika 2015, 2015, (978), pp. 229238. 